\title{
HOW BENEFICIAL IS EARTHQUAKE PREDICTION?
}

Seismological institutions in earthquakeactive regions are used to receiving predictions of impending earthquakes from members of the public, who use a variety of techniques, some physical, some biological, and some psychic. Such preductions are usually dealt with quietly by the seismologists, without the public becoming involved.

Earlier this year, however, much publicity was given by New Zealand news media to a prediction of a major earthquake in a specific part of the country, during a given interval of seven days. This prediction was announced by an overseas scientist, not a specialist in seismology, whose academic title and address added an aura of authenticity to his claim. seismologists working in active seismic areas know how precarious is the balance between keeping the public alert to the ever-present dangers of earthquakes, and evoking unnecessary alarm. Such statements as those recently published here can at the best cause worry and alarm, and at the worst can cause panic, leading to congestion on the roads and casualties among wou 1d-be escapers.

Many earth scientists are working towards a fuller understanding of the earthquake mechanism, and the International Association of Seismology and Physics of the Earth's Interior has set up a Commission of Earthquake Predict ion. Overseas, "prediction" has been used widely as a catch-phrase to attract funds in a competitive scientific market. Much valuable research has come from these prediction programmes, and from them has emerged a much greater appreciation of the physical forerunners that precede earthquakes. In oilfields in the United States, for example, "control" of small earthquakes has been achieved over a limited area by varying the amount of water injected or withdrawn through surrounding wells. Despite such progress, from which a great understanding of earthquake mechanisms is emerging, no significant earthquake has yet been "predicted".

Prediction is often spoken of with an i11deserved reverence, as if it will be the answer to al 1 earthquake problems. It is not al ways clear, however, exactly what its benefits will be. Statistical statements of the expected frequency of occurrence of earthquakes at different places are helpful in assessing earthquake risk, but vague statements such as "a major earthquake is expected in the south of the North Island during the next monthn are of little practical value. It would not be practical to evacuate so large an area for so long a time. Such a statement could possibly be of use to planners in ensuring that adequate supplies of food, emergency stores, clothing and medical supplies were in the area, that nearby military facilities were alerted, and similar general precautions carried out. But only when prediction is well established, and accurate in time, position and magnitude, can any real benefit to the public occur.

Until earthquake prediction becomes reliable and exact, attempts should not be given publicity. Any publicity seeker can gain brief notoriety by announcing that an earthquake is "overdue" or "inevitable". The first statement can have only statistical significance, and the second is meaningless in a seismic area. In a country like New zealand, with moderate earthquake activity, predictors have an easy task, for several hundred shocks a year are large enough to be felt somewhere in the country. Even a minor shock is enough to satisfy a vague prediction, and if no shock should occur, relief softens the recriminations.

For scientists with serious theories of earthquake prediction, there are scientific journals eager to publish reputable work。 If a scientist feels that his conscience forces him to reveal his prediction, the authorities may be told discreetly. Attempts to gain publicity through earthquake predictions bring discredit not only to the individual concerned, but indirectly to the large number of responsible scientists who are working towards a fuller understanding of earthquake mechanism.

In our concern over earthquake effects we should remember that earthquakes themselves only harm people in exceptionally rare cases, such as earthquake-generated landslide or tsunami. Casualties in earthquake arise almost entirely from the failure of man-made structures, whether these be simple huts in a Turkish village or multistoried buildings in Alaska or Japan. At a NATO-sponsored International Meeting on Earthquakes in San Francisco in 1971, Professor Charles Richter expressed the wish that more of the money and effort being expended on earthquake prediction be directed towards making structures safer. We know that weak buildings can be strengthened - the knowledge of when an earthquake will happen will not add strength to weak walls.

The scientific prospects of earthquake prediction are exciting, but fore-knowledge of a disastrous earthquake will not prevent it. From a practical viewpoint, therefore, it could be better to devote more effort to istrengthening and replacing existing weak structures, than to furthering prediction schemes whose aim is to tell us exactly when these structures are likely to fail. 